\title{
Auditory hallucinations and Posttraumatic Stress Disorder within schizophrenia and substance abuse
}

Article

Accepted Version

Steel, C., Haddock, G., Tarrier, N., Picken, A. and Barrowclough, C. (2011) Auditory hallucinations and Posttraumatic Stress Disorder within schizophrenia and substance abuse. Journal of Nervous and Mental Disease, 199 (9). pp. 709-711. ISSN 0022-3018 doi:

https://doi.org/10.1097/NMD.0b013e318229d6e8 Available at https://centaur.reading.ac.uk/21705/

It is advisable to refer to the publisher's version if you intend to cite from the work. See Guidance on citing.

To link to this article DOI: http://dx.doi.org/10.1097/NMD.0b013e318229d6e8

Publisher: Lippincott, Williams \& Wilkins

Publisher statement: Authors final version (postprint) archived here - For final published version see publishers website via DOI.

All outputs in CentAUR are protected by Intellectual Property Rights law, including copyright law. Copyright and IPR is retained by the creators or other copyright holders. Terms and conditions for use of this material are defined in the End User Agreement. 


\section{CentAUR}

Central Archive at the University of Reading

Reading's research outputs online 
Auditory Hallucinations and PTSD

Dr Craig Steel, Department of Psychology, University of Reading, Early Gate, Reading, RG6 6AL. UK. Email: c.steel@ reading.ac.uk.

Auditory Hallucinations and Posttraumatic Stress Disorder within Schizophrenia and Substance Abuse

Craig Steel, PhD, Gillian Haddock, PhD, $\$$ Nicholas Tarrier, PhD, $\ddagger$ Alicia Picken, BSc, $\ddagger$ Christine Barrowclough PhD $\ddagger$

* Department of Psychology, University of Reading, Early Gate, Reading, RG6 6AL UK.

† School of Psychological Sciences, University of Manchester, Zochonis Building, Manchester, M13 9PL.

Send reprint requests to Dr Craig Steel, Department of Psychology, University of Reading, Early Gate, Reading, RG6 6AL. UK. Email: c.steel@ reading.ac.uk.

This study was supported by a grant from the Medical Research Council, UK. 
Auditory Hallucinations and Posttraumatic Stress Disorder within Schizophrenia and

Substance Abuse

\begin{abstract}
There is a high prevalence of traumatic events within individuals diagnosed with schizophrenia, and of auditory hallucinations within individuals diagnosed with posttraumatic stress disorder (PTSD). However, the relationship between the symptoms associated with these disorders remains poorly understood. We conducted a multidimensional assessment of auditory hallucinations within a sample diagnosed with schizophrenia and substance abuse, both with and without co-morbid PTSD. Results suggest a rate of co-morbid PTSD similar to those reported within other studies. Patients who suffered co-morbid PTSD reported more distressing auditory hallucinations. However, the hallucinations were not more frequent or of longer duration. The need for a multidimensional assessment is supported. Results are discussed within current theoretical accounts of traumatic psychosis.
\end{abstract}

Key Words: Schizophrenia, posttraumatic stress disorder, hallucinations, multidimensional.

There is now considerable evidence that individuals diagnosed with a psychotic disorder are more likely to have suffered a traumatic event (Bebbington et al., 2004; 
Jansenn et al., 2004). Recent studies estimate that around 30\% of those diagnosed with schizophrenia will also suffer from co-morbid posttraumatic stress disorder (Mueser et al., 2004; Resnick et al., 2003), although it is likely that the majority of these cases will not be detected by mental health services (Lommen and Restifo, 2009). Such a co-morbid presentation is associated with severe symptomatology, reduced quality of life and increased use of health care services (Fan et al., 2008; Switzer et al., 1999). Similarities within the phenomenology of the symptoms of schizophrenia and PTSD have been observed, including a distinction between positive and negative symptoms within both disorders. More specifically, auditory hallucinations have been reported within up to $50 \%$ of individuals diagnosed with PTSD (Anketell et al., 2010).

The psychiatric assessment of psychotic symptoms is commonly conducted using the positive and negative syndrome scale (PANSS, Kay et al., 1987). However, whilst this measure assesses a wide range of symptoms and functioning, it contains a single item for the assessment of 'hallucinatory behaviour'. This item assesses characteristics such as frequency and duration of voices, which do not reflect the level of emotional distress an individual may suffer (Steel et al., 2007). Therefore, more recent studies have adopted a multidimensional assessment of the positive symptoms of schizophrenia which enables the consideration of a range of variables associated with auditory hallucinations, such as frequency, distress, controllability and impact on functioning (Haddock et al., 1999).

The primary aim of the current study was to explore the relationship between auditory hallucinations and posttraumatic stress disorder within individuals diagnosed with a psychotic disorder. A multidimensional assessment of auditory hallucinations was conducted in order to compare the characteristics of voices within those who 
suffered from PTSD and those who did not. It was hypothesised that there would be a higher prevalence of PTSD within those who reported auditory hallucinations. It was also hypothesised that within the sub-group who reported hallucinations, those who fulfilled the diagnostic criteria for PTSD would suffer from a more frequent, negative and distressing form. This prediction is in line with previous research reporting a higher level of broad psychotic symptoms within this co-morbid group (Fan et al., 2008; Switzer et al., 1999). One possibility is that the group who exhibit co-morbid PTSD suffer from heightened anxiety, in the form of hypervigilance, and that this emotional state increases the level of distress associated with hallucinations. Therefore, a measure of anxiety was employed in order to assess the potential role of heightened arousal as a mediator between PTSD and hallucinatory distress

\section{METHODS}

This study employed an opportunistic sample of patients with psychosis and substance use who were participating in a multi-centred clinical trial evaluating Motivational Interviewing and Cognitive Behaviour Therapy (the MIDAS trial, see Barrowclough et al., 2009 for a description of the trial design and intervention). The primary target of the intervention was substance abuse. For the current study 110 participants from the MIDAS sample were recruited from 4 National Health Service trusts in the north west of England between October 2004 and April 2007. Participants were first recruited into the clinical trial and consented to further assessment for the purposes of this study. Assessments for this study were carried out at the 6 month assessment point of the trial. Ethical permission was obtained from the NHS Eastern MREC. Participants were recruited into the study if they met the following inclusion criteria: 1) DSM-IV diagnostic criteria for schizophrenia, schizophreniform or 
schizoaffective disorder, as assessed by trained research assistants from chart review; 2) were English speaking; 3) had contact with mental health services; 4) were able to give informed consent to take part in the trial; and, 5) alcohol use exceeding 28 units for males, 21 units for females on at least half the weeks in the previous 3 months and/or use of illicit drugs on at least two days per week in at least half the weeks in the 3 months prior to assessment, and met criteria for dependence or abuse assessed by the Structured Clinical interview for DSM. Participants were excluded if there was an organic cause for their psychosis. All participants were living in the community at the time of recruitment and had current contact with mental health services.

Current levels of psychotic symptoms and other psychopathology occurring within the previous week was assessed using the Positive and Negative Syndrome Scale (PANSS, Kay et al., 1987). The multiple dimensions of auditory hallucinations experienced within the previous week were rated using the Psychotic Symptom Rating Scales (PSYRATS; Haddock et al., 1999). The presence of PTSD was assessed using the Posttraumatic Stress Diagnostic Scale (PDS, Foa et al., 1997). Due to recent findings from our research group (Tarrier et al., 2007) indicating trauma specific to the schizophrenia population such as involuntary hospitalisation, and distressing psychotic symptoms and treatments, these experiences were also added to the list of traumatic experiences included in the assessment of PTSD.

Subjects were referred by their mental health care coordinators for involvement in the MIDAS trial. Research assistants recruited individuals after screening their medical notes to check eligibility and assessing whether they met criteria for alcohol and/or drug dependence or abuse. Individuals gave informed consent to be involved in the study for the next 2 years. During baseline assessments for the MIDAS study demographic information was collected. Six months after baseline subjects completed 
the PANSS, PSYRATS and PDS measures for the present study. All measures were administered by trained research assistants in a single session.

\section{RESULTS}

From a total of 166 potentially eligible subjects, 126 individuals consented to the study. Sixteen did not wish to complete the relevant assessments, leaving a sample of 110 . Of these 110 there were 50 participants who experienced auditory hallucinations, which was operationalised as scoring 3 or above on the PANSS hallucinations item, i.e. a rating of 'mild'. The characteristics of the total sample and the sample divided into those with and without auditory hallucinations are presented in Table 1.

Table 1 near here

\section{Occurrence of traumatic events}

One hundred of the $110(91 \%)$ participants had experienced at least 1 traumatic event, with an average of 4.3 (SD 2.4) events being reported, and 31 (28\%) met full criteria for PTSD (Picken and Tarrier, submitted). The prevalence of PTSD within those who reported hallucinations (36\%) was not significantly higher than within those who did not $(22 \%)\left[\chi^{2}(1)=2.8, p=0.1\right]$. 
Characteristics of auditory hallucinations

The PSYRATS ratings and other characteristics of subjects who experienced auditory hallucinations, divided into those with and without PTSD, are reported in Table 2.

Table 2 near here

As can be seen individuals with co-morbid PTSD experienced hallucinations which were more distressing, both in terms of amount $(\mathrm{t}=2.1$, d.f. $=48, \mathrm{p}=0.04)$ and intensity $(t=3.8$, d.f. $=47, p<0.001)$. These were the only significant differences between the two groups.

\section{DISCUSSION}

The results of the current study highlight the importance of the need to consider a multidimensional approach to psychotic symptoms. It is clear that those individuals with co-morbid PTSD experienced auditory hallucinations which were significantly more distressing. However, the PANSS item 'Hallucinatory Behaviour' did not detect this difference. This is likely to be due to the PANSS assessment of hallucinations mainly being based on the dimensions of frequency and duration, which did not differ between the groups and are distinct from the assessment of emotional impact (Steel et al., 2007). It should also be noted that, unlike in previous reports, the group who exhibited co-morbid PTSD did not suffer from a higher level of broad psychotic symptomatology. 
The mechanism through which hallucinations within co-morbid PTSD become more distressing remains to be understood. It is of interest that the content of the voices are not significantly more distressing, and therefore the content does not seem to be mediating the distress. It is also of interest that those with co-morbid PTSD did not exhibit a higher level of anxiety. Therefore, the possibility of the heightened state of arousal associated with PTSD exacerbating more severe hallucinations is not supported. One possibility is that the hallucinatory experiences within the PTSD group are somehow related to past traumatic events and that their presence is associated with a heightened state of vigilance and threat. This explanation is consistent with theories which describe how posttraumatic symptoms may evolve into a psychotic presentation (Morrison, 2001; Steel et al., 2005). The fact that there is no difference between the groups as regards to negative content of voices suggests that it is not the content itself which is driving the increased distress in the co-morbid group. One possible explanation for the role of trauma here may be that the link between trauma and hallucinations is predominantly at the level of emotional themes rather than specific content (Hardy et al., 2004). However, it may also be that that both the PTSD and the non-PTSD group suffer from hallucinations which contain negative content directly related to past stressful events, although these events did not reach the diagnostic criterion for a traumatic event within the non-PTSD group.

At present, there are a large number of potential relationships between traumatic events and the onset and content of subsequent psychotic symptoms. These range from the impact of trauma on physiological processes, such as the hypothalamic-pituitary-adrenal (HPA) axis (Walker and Diforio, 1997) to the role of attachment theory (Read and Gumley, 2008). Whilst theoretical models need development, the current results have some clinical implications. The prevalence of PTSD within the current study (Picken and Tarrier, in press) was in line with the 
results of previous studies (Mueser et al., 2004; Resnick et al., 2003), although the rate of PTSD within the hallucination group was not significantly higher than in those who did not report hallucinations. Given that almost one in three patients exhibit diagnostic levels of PTSD symptoms suggests that psychosis services should engage in routine trauma assessment.

\section{CONCLUSIONS}

A multidimensional approach should be adopted for the assessment of psychotic symptoms. In particular, clinicians should not be unduly focussed on the frequency of symptoms, but also attend to the emotional impact.

\section{REFERENCES}

Anketell C, Dorahy M, Shannon M, Elder R, Hamilton G, Corry M, MacSherry A, Curran D, O'Rawe B (2010) An exploratory analysis of voice hearing in chronic PTSD: Potential associated mechanisms. J of Trauma Diss. 11:93-107.

Barrowclough C, Haddock G, Beardmore R, Conrod P, Craig T, Davies L, Dunn G, Lewis S, Moring J, Tarrier N, Wykes T (2009) Evaluating integrated MI and CBT for people with psychosis and substance misuse: recruitment, retention and sample characteristics of the MIDAS trial. Addict Behav.

Bebbington P, Bhugra D, Bhugha T, Farrel M, Lewis G, Meltzer H, et al. (2004) Psychosis, victimisation and childhood disadvantage: evidence from the second British National Survey of Psychiatric Morbidity. Br J Psychiatry. 185:220-226.

Fan X, Henderson DC, Nguyen DD, Cather C, Freudenreich O, Evins AE, Borba CP, Goff DC (2008) Posttraumatic stress disorder, cognitive function and quality of life in patients with schizophrenia. Psychiatr Res. 159:10-146.

Foa EB, Cashman L, Jaycox L, Perry K (1997) The validation of a self-report measure of posttraumatic stress disorder: the Posttraumatic Diagnostic Scale. Psychol Assess. 9:445-451

Haddock G, McCarron J, Tarrier N, Faragher EB (1999) Scales to measure 
dimensions of hallucinations and delusions: The psychotic symptom rating scales (PSYRATS). Psych Med. 29: 879-89.

Hardy A, Fowler D, Freeman D, Smith B, Steel C, Kuipers E, Garety P, Bebbington $\mathrm{P}$ (2005) Trauma and hallucinatory experience in psychosis. J Nerv Ment Dis. 193: 501- 507.

Janssen I, Krabbendam L, Bak M, Hanssen M, Vollebergh W, Graff R, et al. (2004) Childhood abuse as a risk factor for psychotic experiences. Acta Psychiat Scand. 109:38-45.

Kay SR, Opler LA Lindenmayer JP (1987) The Positive and Negative Syndrome Scale (PANSS) for schizophrenia. Schiz Bull. 13: 261-276.

Lommen, JJ, Restifo K (2009) Trauma and posttraumatic stress disorder (PTSD) in patients with schizophrenia or schizoaffective disorder. Community Ment Health J. 45, 485-496.

Morrison AP (2001) The interpretation of intrusions in psychosis: an integrative cognitive approach to psychotic symptoms. Behav Cog Psychother. 29: 257276.

Mueser KT, Salyers MP, Rosenberg SD, Goodman LA, Essock SM, Osher FC, et al. (2004) Interpersonal trauma and posttraumatic stress disorder in patients with severe mental illness: Demographic, clinical, and health correlates. Schizophr Bull. 30:45-57.

Picken A, Tarrier N (in press) Trauma and co-morbid PTSD in individuals with schizophrenia and substance abuse. Comp Psych.

Read J, Gumley, A (2008) Can attachment theory help explain the relationship between childhood adversity and psychosis? Attach New Dir Psychother Relational Psychoanal. 2: 1-35.

Resnick SG, Bond GR, Mueser K (2003) Trauma and posttraumatic stress disorder in people with schizophrenia. J Abnorm Psychol. 112: 415-423.

Steel C, Garety P, Freeman D, Craig E, Fowler D, Bebbington P, Kuipers E, Dunn $\mathrm{G}$ (2007) The multi-dimensional measurement of the positive symptoms of psychosis. Int J Meth Psychiatr Res. 16: 88-96.

Switzer G, Dew MA, Thompson K, Goycoolea JM, Derricott T, Mullins S (1999) Posttraumatic stress disorder and service utilization among urban mental health center clients. J Traumatic Stress. 12: 25-39.

Tarrier N, Khan S, Cater J, Picken A (2007) The subjective consequences of suffering a first episode of psychosis: Trauma and suicide behaviour. Soc Psych Psychiatr Epid. 42: 29-35.

Walker E, Diforio D. (1997) Schizophrenia: a neural diathesis stress model. Psychol Rev. 104: 667-865. 
Table 1 - Sample characteristics of the total sample and divided into those with and without Auditory Hallucinations

\begin{tabular}{|c|c|c|c|}
\hline & $\begin{array}{c}\text { Auditory } \\
\text { Hallucinations } \\
(n=50)\end{array}$ & $\begin{array}{c}\text { No Auditory } \\
\text { Hallucinations } \\
(n=60)\end{array}$ & $\begin{array}{c}\text { Total sample } \\
\quad(n=110)\end{array}$ \\
\hline \multicolumn{4}{|l|}{ Gender: } \\
\hline Male & $43(86 \%)$ & $56(93 \%)$ & $99(90 \%)$ \\
\hline Female & $7(14 \%)$ & $4(7 \%)$ & $11(10 \%)$ \\
\hline \multicolumn{4}{|l|}{ Age: } \\
\hline Mean (SD) & $36(9.41)$ & $37(10.35)$ & $37(9.95)$ \\
\hline \multicolumn{4}{|l|}{ Diagnosis: } \\
\hline Schizophrenia & $40(80 \%)$ & $47(78 \%)$ & $87(79 \%)$ \\
\hline Schizoaffective & $5(10 \%)$ & $8(13 \%)$ & $13(12 \%)$ \\
\hline Schizophreniform & $1(2 \%)$ & 0 & $1(1 \%)$ \\
\hline Psychosis NOS & $4(8 \%)$ & $5(8 \%)$ & $9(8 \%)$ \\
\hline \multicolumn{4}{|l|}{ Years since onset: } \\
\hline Mean (SD) & $10(9.58)$ & $12(10.22)$ & $11(9.94)$ \\
\hline \multicolumn{4}{|l|}{ Hospitalisations: } \\
\hline Mean (SD) & $4(5.23)$ & $5(7.15)$ & $5(6.34)$ \\
\hline \multicolumn{4}{|l|}{ Substance: } \\
\hline Alcohol & $32(64 \%)$ & $35(58 \%)$ & $67(61 \%)$ \\
\hline Cannabis & $12(24 \%)$ & $14(23 \%)$ & $26(24 \%)$ \\
\hline Ecstasy & $2(4 \%)$ & $7(12 \%)$ & $9(8 \%)$ \\
\hline Heroin & $1(2 \%)$ & $1(2 \%)$ & $2(2 \%)$ \\
\hline Amphetamine & $3(6 \%)$ & $3(5 \%)$ & $6(5 \%)$ \\
\hline PTSD Diagnosis & $18(36 \%)$ & $13(22 \%)$ & $31(28 \%)$ \\
\hline
\end{tabular}


Table 2 - PSYRATS ratings for auditory hallucinations divided into those with and without PTSD

\begin{tabular}{ccc}
\hline & $\begin{array}{c}\text { PTSD } \\
(\boldsymbol{n = 1 8})\end{array}$ & $\begin{array}{c}\text { Non-PTSD } \\
(\boldsymbol{n}=\mathbf{3 2})\end{array}$ \\
\hline PSYRATS & $1.7(1.13)$ & $1.8(1.06)$ \\
Frequency & $2.6(1.15)$ & $2.5(1.14)$ \\
Duration & $2.2(1.26)$ & $2.6(1.32)$ \\
Location & $1.9(0.83)$ & $1.7(0.73)$ \\
Loudness & $2.6(1.15)$ & $2.6(1.27)$ \\
Beliefs re-origin of voices & $2.9(1.41)$ & $2.4(1.77)$ \\
Amount of Negative Content & $2.9(1.37)$ & $2.2(1.74)$ \\
Degree of Negative Content & $2.9(1.06)^{*}$ & $2.1(1.78)^{*}$ \\
Amount of Distress & $2.9(1.00)^{* *}$ & $1.6(1.45)^{* *}$ \\
Intensity of Distress & $1.5(0.71)$ & $1.3(0.82)$ \\
Disruption to Life & $2.8(1.20)$ & $3.1(1.30)$ \\
Controllability & & \\
PANSS & $17.9(3.90)$ & $18.4(4.87)$ \\
Positive & $4.3(0.83)$ & $4.2(0.92)$ \\
Hallucinatory Behaviour & $3.8(1.65)$ & $3.2(1.56)$ \\
Anxiety & $12.9(3.87)$ & $14.8(4.66)$ \\
Negative & $35.3(5.86)$ & $33.2(6.47)$ \\
General & $65.9(7.93)$ & $66.5(12.08)$ \\
Total & & \\
\hline
\end{tabular}

$* \mathrm{p}<0.05 ; * * \mathrm{p}<0.01$ 